\title{
PROGRESS IN RADIOCARBON DATING THE SHROUD OF TURIN
}

\section{H E GOVE}

\author{
Nuclear Structure Research Laboratory, University of Rochester \\ Rochester, New York 14627
}

\begin{abstract}
An account is presented of the current status of the project to radiocarbon date the cloth of the shroud of Turin. The procedures dictated by the Turin ecclesiastical authorities to accomplish this are discussed. It will be concluded that the original protocol, as agreed to by all parties at the Turin Workshop in 1986, suggested a preferable procedure. However, if the three laboratories, who accepted the task of dating the shroud, obtain the same age for the shroud and the three control samples within a standard deviation or two completely independently, most knowledgeable scientists will probably accept the results.
\end{abstract}

\section{INTRODUCTION}

In May 1977, Purser et al (1977) and Bennett et al (1977) showed, at the University of Rochester, that by exploiting the instability of the $\mathrm{N}^{-}$ion and the elimination of molecular interferences, ${ }^{14} \mathrm{C}$ could be detected at natural abundances and that the background was very, small. As a result of a popular account in Time magazine (1977) of this new accelerator mass spectrometry (AMS) technique for carbon dating, the author received a letter from the General Secretary of the British Turin Shroud Society, the Rev H D Sox (pers commun, June 24, 1977) asking whether it could be applied to establish the age of the cloth comprising the Turin shroud. This led to a complex chain of events, one of which was a workshop held in Turin, Italy on September 29 through October 1, 1986, which produced a protocol for carrying out such a measurement (Gove, 1987). This protocol was subsequently rejected by Turin ecclesiastical authorities. The seven laboratories proposed in the protocol to carry out the measurements were reduced to three and other changes were made. An outline of the new procedures dictated by Turin and finally agreed to by the three chosen laboratories and the British Museum in its coordinating role was provided by the member of that institution who would be directly involved (Tite, 1988). Comments on these were provided by the author (Gove, 1988).

A discussion of the reasons one might wish to apply this AMS technique to the Turin Shroud, which clearly is of minimal interest scientifically, have been presented (Gove, 1987). Briefly, they reflect the enormous interest the general public has in this remarkable artifact, the fact that it demands the use of very small samples, the increasing intellectual interest among scholars in the shroud (Dale, 1987), and the stringent test it would provide for the credibility of small-sample dating by AMS.

\section{COMPARISON OF DATING PROCEDURES}

It is generally known by now that the three AMS laboratories, namely those at the Universities of Arizona and Oxford and the ETH at Zürich, are presently engaged in establishing the age of the linen cloth that comprises the main body of the Turin shroud on which is imprinted the image of a 
crucified man. At the invitation of Professors Donahue and Damon, codirectors of the Arizona AMS facility, the author was present at the first measurement of the shroud on Friday, May 6, 1988 at 9:50 AM at the University of Arizona. Their measurements are now completed and have been submitted to the British Museum. The measurements at the ETH Zurich are well along and should be completed very soon. The AMS facility at the University of Oxford has not yet begun the measurements. The only deadline for announcing the final results that has been given is the end of the year, but it is likely they will be available before the date on which the present Cardinal of Turin officially retires as Archbishop of that diocese sometime in October.

As one who played a leading role in developing the AMS technique that permits precious artifacts like the shroud to be "non destructively" dated, as the chief spokesman and coordinator for dating the shroud, and as head of one laboratory rejected by Turin from participating in the enterprise, it seems appropriate for the author to make few comments on various aspects of the affair. It seems gratuitous to remark that all three laboratories chosen by Turin are as qualified to date the shroud as were the four that were eliminated. If all three laboratories arrive at the same date for the shroud and the control samples within a standard deviation or two and if there has been no collusion between them, as surely there will not be, then as far as the present author is concerned, the result will be credible. Whether the public at large will find it similarly credible because of some or all of the points to be discussed below is, perhaps, less certain.

The Vatican empowered the Archbishop of Turin to make all decisions concerning the shroud. He and his advisors were thus presented with the alternative of accepting the Turin Workshop protocol or of inventing a new one. They chose the latter and for that deserve to be criticized. In what follows, this criticism is directed to the appropriate Turin ecclesiastic authorities and not to the people connected with the three laboratories who are presently engaged in dating the shroud. The heads of these laboratories made a vigorous representation to the Archbishop of Turin (Donahue, pers commun, Nov 5,1987$)$ to persuade him to reverse his decision to abrogate the Turin protocol (Gove, 1987) but to no avail. Although the author did hope the three laboratories would then decline the Archbishop's dictum, they reluctantly decided to proceed with the measurement. Whether that was a wise decision or not is yet to be tested.

First among the points to be considered is the fact than the Pontifical Academy of Sciences, after organizing and chairing the workshop in Turin which arrived at an exemplary protocol for dating the shroud (Gove, 1987), was prevented by Turin from playing any further role in the dating enterprise. The Pontifical Academy of Sciences is the only scientific body connected with the Roman Catholic Church that has any international standing. Its elimination from participation by Turin was inexplicable. It did, however, have the effect of making the dating of the shroud more of a hometown effort. Other changes in the Turin Workshop protocol reinforce that parochial approach as further described.

Second, the internationally renowned textile expert from the AbeggStiftung, Bern, Switzerland selected by the Pontifical Academy of Sciences 
to be present at the Turin workshop and accepted by the workshop to supervise removal of suitable samples from the shroud for dating was rejected by Turin in favor of individuals handpicked by them. Again, no reason was given. The sample was removed on April 21, 1988 by Professor Giovanni Riggi, a Turin microanalyst, and at least one of the textile people was also from Turin; the other was from France. However, despite the previous statement by Archbishop Anastasio Cardinal Ballestrero (pers commun, Oct 10, 1987, "The instructions from the Holy See do not deem it necessary for representatives of the measurement laboratories to attend the sample-taking operations," fortunately, the sampling process ultimately followed the protocol recommended by the Turin Workshop. Present also at the cutting were the representative of the British Museum, the Cardinal of Turin, his science advisor and a handful of other people. The President of the Pontifical Academy of Sciences, despite his being invited by the Cardinal to be present as his guest, was notably absent. The entire sampletaking procedure was privately videotaped under the direction of Professor Riggi. The piece of cloth removed was cut from the main body of the shroud at the hem close to where the sample was removed for examination by Professor Gilbert Raes in 1973. Three equal pieces were cut from this sample by the representative of the British Museum, weighed, wrapped in aluminum foil and sealed in numbered stainless steel containers all in view of the laboratory representatives and immediately handed to them. Two of the control samples supplied by the Museum were similarly treated. A third control sample was supplied by a radiocarbon laboratory in France. The fact that all three laboratories received a sample from essentially the same place on the shroud, and all will use essentially the same cloth cleaning procedures, means that any contamination that is not removed by such cleaning methods will equally affect all three measurements making them in agreement but wrong. Although this is unlikely, it could provide a rationale for discrediting whatever result is obtained by those who disagree with it.

Third, as made clear by Tite (1988) and from the above, no attempt is being made to carry out a "blind" dating of the shroud as recommended in the Turin Workshop Protocol (Gove, 1987), since neither the shroud sample nor the two control samples supplied by the Museum were unravelled. The shroud weave is readily identifiable. More surprisingly, the ages of the three control samples were given in the English-language edition of L'Osservatore Romano (1988). The ascribed ages of the control samples should be accepted circumspectly, however.

Fourth, the use of both decay counting using very small proportional counters and accelerator mass spectrometry (AMS) was changed to AMS only. The two methods are distinct and independent. One of the small counter laboratories that was eliminated (Harwell) has more carbon dating experience than the other six of the original seven put together. Rumors that Turin was having second thoughts about the lack of wisdom of this decision, whether true or not, unfortunately did not result in it being reversed. Including Harwell would have indeed been a wise move if for no other reason than to demonstrate once more to the skeptics that AMS and decay counting give the same result. 
Fifth, and most important of all, reducing the number of laboratories independently making the measurement from 7 to 3 eliminates the possibility of detecting an "outlier" result from one of the laboratories. Such an outlier result occurred in the interlaboratory comparisons organized by the British Museum several years ago and reported at the 12th International Radiocarbon Conference held in Trondheim in 1985 (Burleigh, Leese \& Tite, 1986). If such an outlier result is obtained by any one of the three laboratories this time, the final result will be worthless. No explanation has ever been advanced by the Turin authorities for this decision.

Sixth, as made clear by Tite (1988), the final data analysis will be carried out in the manner recommended in the Turin protocol (Gove, 1987) with the important exception that the Pontifical Academy of Sciences will no longer be involved. Thus, the only independent person involved in the decision as to how the final numbers translate into an age for the shroud will be the representative of the British Museum. The other organization involved will be the Institute of Metrology "G Colonnetti" in Turin, another member of the home team. This, of course, will keep the enterprise even more "in the family." However, it should be noted that representatives of the three laboratories must also approve the manner in which the final numbers translate into an age for the shroud.

\section{CONSERVATION OF THE SHROUD}

What further steps should be taken as soon as the age of the shroud is determined, assuming the present set of measurements provides a credible result? If the age of the shroud comfortably and credibly encompasses the date of Christ's crucifixion (which itself is somewhat uncertain), then no further scientific tests should be performed on the shroud unless authorized by a high-level scientific commission appointed preferably by the President of the Pontifical Academy of Sciences. In particular, any further "scientific" measurements of the kind carried out in 1978 by self-appointed religious zealots should be studiously eschewed as, of course, they should have been all along. If the age clearly excludes the possibility that it was Christ's shroud, it should then be thoroughly examined by art experts. For example, Anthony Harris (1988) suggested that the shroud was "painted" by Leonardo da Vinci toward the end of the 15th century on linen of unknown vintage originating in the region of Palestine. Only highly qualified art and textile experts might be able to illuminate this question.

Whatever the age of the shroud, it is arguably a very precious artifact; however, its custodial treatment both in France and in Turin since its existence was first revealed ca AD 1353 scarcely testifies to that. After it successfully weathered, with scarcely any damage to the image, a fire in 1532 in the chapel in Chambery, France, where it was stored in a silver cask, the Poor Clare nuns patched it and added a backing cloth. In 1535 it was transported to Turin. It presently rests in a wooden casket ornamented with silver within an iron chest behind an iron grill in the Royal Chapel of the Cathedral of John the Baptist in Turin. It lies in this casket covered with a red silk cloth and rolled around a wooden cylinder. No humidity or temperature control exists in the Chapel and little or no other conservation measures are in 
effect. It is a tribute to the sturdiness of linen that it has so well survived even its historical age.

What is even more surprising than the casual way in which the shroud is stored in Turin is the even more casual way in which a piece of the main body of the shroud was removed in 1973 for examination by a textile expert in Belgium. The whereabouts of this piece, almost as large as the one recently removed for carbon dating, were so poorly monitored, that although it was allegedly returned to Turin, it was considered too suspect to ever be used for carbon dating. Another example of the remarkable way in which the "Pontifical Custodian of the Shroud of Turin" carries out his duties are the tests which were permitted in 1978. Among other things, they involved bathing the shroud in potentially damaging electromagnetic radiation of various frequencies including ultra-violet and X-rays. It is clear from the shroud's custodial history that one of the first orders of business after the age of the cloth is established should be to seek the advice of expert conservators to ensure the shroud is preserved for the future.

\section{CONCLUSIONS}

The radiocarbon dating of the Turin shroud which the author had envisaged as a convincing test of the power and efficacy of AMS for carbon dating small samples of precious artifacts turned out to be a complex and, in some respects, a rather divisive enterprise. It may be that, although there are many questions that science can answer, there are some that it need not and, indeed, probably should not tackle. Be that as it may, whatever age the shroud turns out to be, the result will be contentious in some quarters, in part because of the inadequacies of the procedures being followed. There is a reasonable chance, however, that the three laboratories will independently produce concordant results and, in this circumstance, at least the scientific community is likely to find the dates credible. ${ }^{1}$

\section{REFERENCES}

Bennett, C L, Beukens, R P, Clover, M R, Gove, H E, Liebert, R P, Litherland, A E, Purser, K H and Sondheim, W E, 1977, Radiocarbon dating using electrostatic accelerators: Negative ions provide the key: Science, v 198, p 508-510.

Burleigh, R, Leese, M and Tite, M, 1986, An intercomparison of some AMS and small gas counter laboratories, in Stuiver, $\mathrm{M}$ and $\mathrm{Kra}, \mathrm{R} \mathrm{S}$, eds, Internatl ${ }^{14} \mathrm{C}$ conf, 12 th, Proc: Radiocarbon, v 28, no. 2A, p 571-577.

Dale, W S A, 1987, The shroud of Turin: Relic or icon?: Nuclear Instruments \& Methods, v B29, p 187-192.

Gove, H E, 1987, Turin workshop on radiocarbon dating the Turin shroud: Nuclear Instruments \& Methods, v B29, p 193-195.

1988, Radio-carbon dating the shroud: Nature, v 333, p 110.

Harris, A, 1988, The sacred virgin and the holy whore: London, Sphere Books Ltd.

L'Osservatore Romano, 1988, Samples of the shroud of Turin taken for scientific dating: May 2.

Purser, K H, Liebert, R B, Litherland, A E, Beukens, R P, Gove, H E, Bennett, C L, Clover, M R and Sondheim, W E, 1977, An attempt to detect stable $\mathrm{N}^{-}$ions from a sputter ion source and some implications of the results for the design of tandems for ultra-sensitive carbon analysis: Rev Phys Appliquée, v 12, p 1487-1492.

Time magazine, 1977, New dating game: June 27, p 72.

Tite, M S, 1988, Turin shroud: Nature, v 332, p 482.

${ }^{1}$ Note added in proof: The date of the shroud announced by Turin and reported in the Oct 14, 1988 edition of the New York Times was AD 1260-1390 at a 95\% confidence level. 